\title{
Potentiated Reinstatement of Cocaine-Seeking Behavior Following D-amphetamine Infusion into the Basolateral Amygdala
}

\author{
Christopher C Ledford', Rita A Fuchs' and Ronald E See, \\ 'Department of Physiology and Neuroscience, Medical University of South Carolina, Charleston, SC, USA
}

\begin{abstract}
Reinstatement of extinguished drug-seeking behavior following chronic drug self-administration has been demonstrated in rats in the presence of conditioned cues. This experimental model of cue-induced relapse can be used to assess the neural circuitry involved in relapse. We have previously shown that blockade of dopamine DI receptors in the basolateral amygdala (BLA) abolishes conditioned cue-induced reinstatement of cocaine-seeking behavior. The present study tested the hypothesis that D-amphetamine-induced facilitation of monoamine neurotransmission in the BLA would potentiate conditioned cue-induced reinstatement of extinguished drug-seeking behavior. During daily self-administration sessions over 10 consecutive days, rats pressed a lever to receive cocaine infusions (0.2 mg/ $0.05 \mathrm{ml}$ ) paired with a light + tone compound stimulus. Following self-administration, rats underwent daily extinction sessions, during which no stimuli were presented. On the test days, rats received intra-BLA D-amphetamine ( 10 or $30 \mu g / s i d e)$ or vehicle infusions followed by extinction or conditioned cue-induced reinstatement testing. D-amphetamine infusions did not alter extinction responding relative to vehicle infusions. During reinstatement testing, conditioned cue presentation significantly increased responding over extinction levels, and intra-BLA D-amphetamine produced a dose-dependent increase in lever responding relative to vehicle infusions. These findings suggest that enhanced monoamine tone in the BLA potentiates the motivational effect and/or salience of cocaine-paired cues during reinstatement.

Neuropsychopharmacology (2003) 28, I72I-1729, advance online publication, 09 July 2003; doi: I 0.1 038/sj.npp. 1300249
\end{abstract}

Keywords: D-amphetamine; basolateral amygdala; cocaine; dopamine; reinstatement; relapse

\section{INTRODUCTION}

Relapse to drug-seeking and drug-taking presents a major challenge to the treatment of addiction to drugs of abuse, such as cocaine. Among the variables that contribute to drug relapse, exposure to drug-associated environmental cues is a very powerful factor (O'Brien et al, 1990; Childress et al, 1993). In the course of chronic cocaine use, initially neutral stimuli (eg paraphernalia or drug-taking environment) are repeatedly paired with the effects of the drug, thus acquiring conditioned motivational properties over time (Stewart et al, 1984). In cocaine users, exposure to stimuli previously paired with drug-taking behavior can then elicit pronounced craving and conditioned physiolo-

\footnotetext{
*Correspondence: Dr RE See, Department of Physiology and Neuroscience, Medical University of South Carolina, 173 Ashley Avenue, Charleston, SC 29425, USA, Tel: + I 843792 2487, Fax: + I 843792 4423, E-mail: seere@musc.edu

Received 29 January 2003; revised 04 May 2003; accepted 08 May 2003

Online publication: 27 May 2003 at http://www.acnp.org/citations/ Npp0 12003463/default.pdf
}

gical arousal (Childress et al, 1988, 1993; O'Brien et al, 1990, 1992).

Similar to humans, environmental stimuli (eg lights or tones) consistently paired with drugs of abuse elicit reinstatement of extinguished drug-seeking behavior (eg nonreinforced lever presses) in laboratory animals (Davis and Smith, 1976; de Wit and Stewart, 1981; Meil and See, 1996; See et al, 1999). In this model, rats are trained to lever press for intravenous cocaine infusions paired with a compound light + tone stimulus during daily self-administration sessions. The self-administration days are followed by extinction days, during which lever responding declines and extinguishes in the absence of drug reinforcement. On the test day, drug-seeking behavior is measured in the presence of the compound stimulus presented response contingently. It is assumed that drug-seeking behavior is an index of incentive motivation for cocaine. The ability of drug-paired stimuli to elicit drug-seeking behavior in animals is reliable, robust, and persistent over time. One study has even demonstrated reinstatement in response to a drug-predictive stimulus 4 months after cessation of cocaine taking (Ciccocioppo et al, 2001). The conditioned cued reinstatement model thus possesses strong predictive 
and face validity in relation to cue-induced relapse in humans (Markou et al, 1993; Carroll and Comer, 1996; Fuchs et al, 1998).

A brain structure that has been implicated in the reinstatement of drug-seeking behavior is the basolateral amygdala (BLA), which comprised of the lateral and basal nuclei of the amygdala complex. Evidence suggests that the BLA is critical for a variety of stimulus-reward associations. For instance, lesions of the BLA do not disrupt the ability of primary reinforcers (Whitelaw et al, 1996; Meil and See, 1997), but impair the ability of secondary reinforcers (Cador et al, 1989; Everitt et al, 1989), to control goaldirected behavior. BLA lesions suppress second-order responding for conditioned reinforcers associated with sexual reinforcement (Everitt et al, 1989) or water reward (Cador et al, 1989). Lesions of the BLA also impair appetitive Pavlovian conditioning and first-order conditioned reinforcement following postconditioning devaluation of a food-unconditioned stimulus (Hatfield et al, 1996). Lesions of the BLA severely impair acquisition of cocaine self-administration under second-order schedule of reinforcement, thus indicating the importance of this limbic structure in mediating conditioned reinforcing effects of drug-paired cues (Whitelaw et al, 1996). Temporary inactivation of the BLA by the sodium channel blocker, tetrodotoxin, during classical conditioning sessions where cocaine infusions were paired with light and tone disrupted the acquisition and expression of cue reinstatement of drugseeking behavior (Kruzich and See, 2001). Furthermore, Fos protein expression is increased in the BLA in response to exposure to cocaine-associated stimuli (Neisewander et al, 2000). Similarly, the amygdala becomes highly activated upon exposure to drug-paired cues in the brains of human cocaine users (Grant et al, 1996; Childress et al, 1999). Taken together, these findings demonstrate the importance of the BLA in stimulus-reward associations.

Dopamine (DA) neuronal terminals are densely localized in the BLA (Fallon et al, 1978; Brinley-Reed and McDonald, 1999). Only when animals self-administer cocaine, as opposed to receiving passive cocaine infusions, are DA levels increased in the amygdala, suggesting that increases in DA neurotransmission in the amygdala are linked to drug-taking and perhaps drug-seeking behavior (Wilson et al, 1994). Consistent with the idea that BLA DA is important in cue-induced cocaine-seeking behavior, intraBLA infusion of SCH 23390, a selective DA D1 receptor antagonist, abolished cue-induced reinstatement (See et al, 2001). In the present study, D-amphetamine, a nonspecific indirect DA agonist, was infused into the BLA to increase extracellular DA locally, in order to further investigate the role of $\mathrm{DA}$ in the BLA. Intra-BLA D-amphetamine was hypothesized to enhance cocaine-seeking behavior in the presence of cocaine-associated cues.

\section{METHODS}

\section{Subjects}

Male Sprague-Dawley rats ( $N=40$; Charles River), weighing 275-350 $\mathrm{g}$ at the time of surgery, were individually housed and maintained on a 12 -h reverse light/dark cycle (lights on at 1800). All protocols were approved by the Institutional
Animal Care and Use Committee of the Medical University of South Carolina, and followed the guidelines of the 'Guide for the Care and Use of Laboratory Rats' (Institute of Laboratory Animal Resources on Life Sciences, National Research Council, 1996).

\section{Food Training}

Rats were food restricted to approximately $90 \%$ of their ad libitum weight for 2 days prior to food training and trained to lever press for 45-mg food pellets (formula A/I; Research Diets Inc., New Brunswick, NJ). The training took place on a fixed ratio 1 (FR1) schedule during an overnight session (16h), during which no stimuli were presented. Subjects who did not meet a minimum criterion of $>100$ reinforced responses/session were given an additional training session. After food training, the food hoppers were removed from the chambers and replaced with metal panels. Rats were maintained on 20-30 g of rodent chow per day for the duration of the study.

\section{Surgery}

At 1 day after the completion of food training, rats were anesthetized with intraperitoneal ketamine $(64.68 \mathrm{mg} / \mathrm{kg})$, xylazine $(1.26 \mathrm{mg} / \mathrm{kg})$, and Equithesin $(1 \mathrm{ml} / \mathrm{kg})$ prior to surgical implantation of indwelling i.v. catheters. Catheters were constructed from Silastic laboratory grade tubing (0.64 mm i.d., 1.19 mm o.d.; Dow Corning, Midland, MI) attached to a 22-gauge cannula (Plastics One Inc., Roanoke, VA). The catheter/cannula assembly was affixed to a polypropylene mesh (Small Parts, Miami Lakes, FL) with cranioplastic cement. A hardened silicon gel (Silicone sealant; General Electric Sealants and Adhesives, Huntersville, NC) nodule was affixed to the catheter $33 \mathrm{~mm}$ from the tip of the catheter. The catheter was implanted into the right jugular vein and secured in place with silk suture around the silicon nodule. The Silastic tubing ran under the skin to an exit point in the mid-scapular region, where the opening of the threaded cannula was covered with a threaded plastic cap when not in use. Immediately following catheter implantation, rats were mounted into a stereotaxic apparatus and 26-gauge stainless-steel guide cannulae were bilaterally aimed $2 \mathrm{~mm}$ above the $\mathrm{BLA} \quad(\mathrm{AP}=-2.7$; $\mathrm{ML}= \pm 5.0 ; \mathrm{DV}=-6.6$, relative to bregma, Paxinos and Watson, 1986). The guide cannulae were held in place with cranioplastic cement anchored to the skull with three steel screws. Stainless-steel stylets (Plastics One Inc.) were inserted into the guide cannulae following surgery. Rats were infused i.v. with $0.1 \mathrm{ml}$ each of cefazolin $(100 \mathrm{mg} / \mathrm{ml})$ and heparinized saline $(70 \mathrm{U} / \mathrm{ml})$ twice daily during a 4-day recovery period, in order to prevent blockage of the catheter. Catheter patency was verified by infusing $0.1 \mathrm{ml}$ of methohexital sodium $(10 \mathrm{mg} / \mathrm{ml}$, i.v.; Eli Lilly and Co., Indianapolis, IN), which produces temporary loss of muscle tone.

\section{Cocaine Self-Administration}

Cocaine self-administration training was conducted in standard operant conditioning chambers $(30 \times 20 \times 24 \mathrm{~cm}$; Med Associates, St Albans, VT). Each chamber contained 
two levers $(7 \mathrm{~cm}$ above the chamber floor) on either side of a food pellet receptacle (the food receptacle was present only during food training). A white circular stimulus light $(2.5 \mathrm{~W}, 24-\mathrm{V}$ bulb) was located $7 \mathrm{~cm}$ above the active lever, and a red house light $(2.5 \mathrm{~W}, 24-\mathrm{V}$ bulb) was located on the wall on the opposite end of the chamber. The infusion line was attached to a liquid swivel (Instech, Plymouth Meeting, PA) mounted on a suspended counterbalance. The selfadministration apparatus was enclosed in a sound-attenuating chamber (Med Associates). Cocaine hydrochloride $(4 \mathrm{mg} / \mathrm{ml}$; National Institute on Drug Abuse, Research Triangle Park, NC) was delivered using a computercontrolled infusion pump located outside the soundattenuating chamber. The entire system was computer integrated using Schedule Manager for Windows (version 2.09; Med Associates).

Rats self-administered cocaine on 10 consecutive days during 2-h sessions. Rats received $0.1 \mathrm{ml}$ of heparinized saline $(10 \mathrm{U} / \mathrm{ml}$, i.v.) prior to each self-administration session. The animals were then connected to the drug infusion line and the session was initiated. Each session began with illumination of the red house light that remained lit for the entire session. Responses on the right (active) lever resulted in delivery of a cocaine infusion $(0.2 \mathrm{mg} /$ $0.05 \mathrm{ml}$ bolus) over $2 \mathrm{~s}$; this training was accomplished using an FR1 schedule. Responses on the left lever had no programmed consequences, but were recorded. Each infusion was paired with a 5-s compound stimulus presentation, consisting of the white stimulus light over the right lever and a tone $(2 \mathrm{kHz}, 78 \mathrm{~dB})$ delivered via a programmable audio generator (ANL-926; Med Associates). Following cocaine delivery and stimulus presentation, responses on the active lever had no programmed consequences (no cocaine or stimulus delivery) for $40 \mathrm{~s}$, but lever responses were recorded. Following each selfadministration session, rats were administered $0.1 \mathrm{ml}$ of cefazolin and $0.1 \mathrm{ml}$ of heparinized saline $(70 \mathrm{U} / \mathrm{ml})$ i.v., and catheter ports were closed to maintain patency.

\section{Extinction}

Following self-administration training, all animals experienced daily 2-h extinction sessions. During the extinction sessions, responding on either lever had no programmed consequences. In order to acclimatize the animals to the intracranial infusion procedure, all animals were given a sham infusion just prior to the fifth extinction session. The sham infusion procedure consisted of inserting the infusion cannulae into the guide cannulae and gently restraining the animal for $4 \mathrm{~min}$. The infusion cannulae (33 gauge) projected $2 \mathrm{~mm}$ below the tip of the guide cannulae. Prior to testing, the animals experienced a minimum of 6 extinction days. If necessary, additional days of extinction were given until the rats reached a response criterion of less than or equal to 20 responses/day on 2 consecutive days.

\section{Testing of Responding after Intracranial Infusions}

After extinction criteria were met, there were a total of 4 test days, two under extinction conditions (lever presses did not elicit cue presentation) and 2 days under conditioned cue conditions (cues presented response contingently). For testing of response under extinction and conditioned cue conditions, animals were divided into low-dose amphetamine $(10 \mu \mathrm{g} / 0.5 \mu \mathrm{l} / \mathrm{side}, N=15)$ or high-dose amphetamine $(30 \mu \mathrm{g} / 0.5 \mu \mathrm{l} /$ side, $N=18)$ treatment groups. The amphetamine doses were selected based on previous studies that used intracranial D-amphetamine to elicit behavioral potentiation in conditioned reinforcement paradigms (Taylor and Robbins, 1984, 1986; Cador et al, 1991). In addition, a separate control group was tested that never received amphetamine during testing sessions (phosphate-buffered saline (PBS) vehicle only, $0.5 \mu \mathrm{l} /$ side, $N=7$ ). Following intracranial infusion on test days, half of the animals in each group initially experienced extinction conditions, while the other half initially experienced conditioned cue conditions. Additionally, in the two amphetamine groups, half of the animals were infused with amphetamine on the first day of either test conditions and the other half were infused with vehicle. Thus, the testing was counterbalanced for test days (cues vs no cues), and in the amphetamine groups, amphetamine $v s$ vehicle infusion.

Immediately prior to a test session, infusion cannulae (33 gauge) were bilaterally inserted into the guide cannulae such that the tip of the injector extended $2 \mathrm{~mm}$ below the tip of the guide cannulae. The injection cannulae were connected to gastight syringes ( $10 \mu \mathrm{l}$; Hamilton, Reno, $\mathrm{NV}$ ) set in a PHD 2000 infusion pump (Harvard Apparatus, Holliston, MA). Infusions were delivered at a volume of $0.5 \mu \mathrm{l}$ over $2 \mathrm{~min}$. The infusion cannulae were left in place for $1 \mathrm{~min}$ before and after infusions. After the infusion, cannulae were removed, stylets were inserted, and the animals were placed into the chamber for testing. Prior to each test session, rats received additional extinction days until they reached the extinction criterion.

\section{Locomotor Activity Testing}

The effects of intra-BLA D-amphetamine on general motor activity were assessed $48 \mathrm{~h}$ after the last reinstatement test session. The animals were infused with $\mathrm{D}$-amphetamine (10 or $30 \mu \mathrm{g} /$ side) or PBS vehicle. Immediately after the infusion, the animals were placed in an open field (Plexiglas enclosure $40.8 \mathrm{~cm} W \times 40.8 \mathrm{~cm} L \times 37.5 \mathrm{~cm} H$ ) photo beam activity system (San Diego Instruments, Inc., San Diego, CA). The total number of photo beam breaks was recorded for $1 \mathrm{~h}$ by a computer program.

\section{Histology}

After the last test session, rats received an overdose of Equithesin. Rats were then perfused with PBS and 10\% formaldehyde. Brains were then extracted and stored in 10\% formaldehyde. Coronal sections $(75 \mu \mathrm{m})$ were cut using a vibratome, mounted onto gelatin-coated slides, and stained with cresyl violet. Slides were examined to determine the most ventral point of the infusion cannula tracts. Data of subjects with misplaced cannulae were omitted from data analysis and those subjects are not reported in the numbers above.

\section{Data Analysis}

$t$-Tests were used to check for test day order effect between groups. Analyses of variance (ANOVA) were used to 
analyze responses on the active and inactive levers with lever (active, inactive), day, test day (last self-administration day, last extinction day, amphetamine test day, vehicle test day), and time (10- or 30-min bins) as within-subject factors and group $(0,10,30 \mu \mathrm{g} /$ side of D-amphetamine) as a between-subject factor, where appropriate. Interaction effects were further investigated using simple main effect tests ( $t$-test) or the Tukey HSD post hoc tests, where appropriate.

\section{Results}

\section{Histology}

A schematic illustrating cannula placements in the brains of rats who received 0,10 , or $30 \mu \mathrm{g} /$ side of $\mathrm{D}$-amphetamine is shown in Figure 1. Guide cannula tracts were observed in the parietal cortex, caudate-putamen, and the lateral/ basolateral amygdaloid complex.

\section{Self-Administration}

Rats in each group exhibited stable responding during the last three self-administration sessions, with a within-subject variability of less than $10 \%$ in daily cocaine intake. There was no difference in cocaine intake between the groups. Collapsed across groups, the mean number of daily cocaine infusions $( \pm$ SEM) was $29.51 \pm 0.93(18.60 \pm 0.53 \mathrm{mg} / \mathrm{kg}$ per $2 \mathrm{~h}$ session). A $2 \times 3 \times 3$ mixed factor ANOVA of lever presses on the last 3 days of self-administration revealed only a significant lever main effect $\left(\mathrm{F}_{(1,37)}=258.04\right.$,

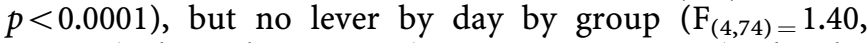

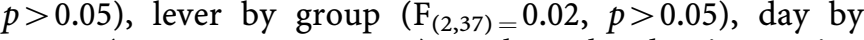
group $\left(\mathrm{F}_{(4,74)}=0.90, p>0.05\right)$, or lever by day interaction effects $\left(\mathrm{F}_{(2,74)}=0.01, p>0.05\right)$. There were also no day $\left(\mathrm{F}_{(2,74)}=0.28, p>0.05\right)$ or group main effects $\left(\mathrm{F}_{(2,37)}=0.23\right.$, $p>0.05)$. Thus, animals responded more on the active lever than on the inactive lever, regardless of day, and the three groups did not differ in cocaine self-administration history.

\section{Extinction}

Upon removal of cocaine reinforcement, active lever responding for all groups decreased over the course of daily extinction sessions (Figure 2). A $2 \times 2 \times 3$ mixed factor

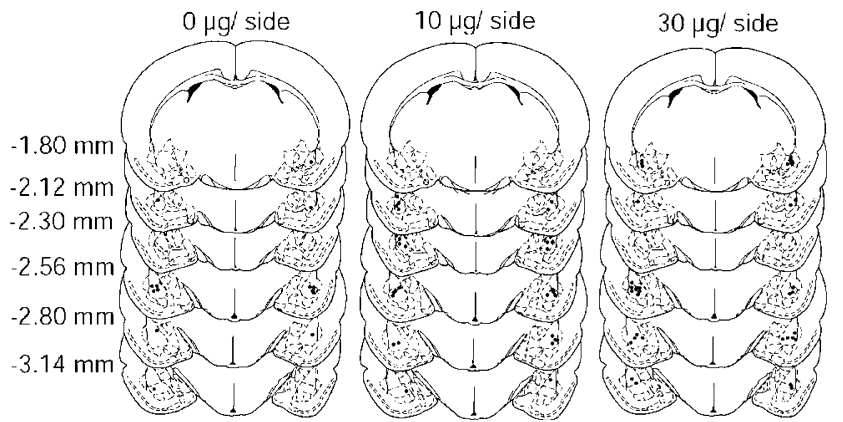

Figure I Schematic representation of cannula placement. Circles represent the most ventral point of the injection cannula tracks in the brains of animals from the 0,10 , and $30 \mu \mathrm{g} /$ side amphetamine groups. The numbers to the left of the schematic sections represent the approximate distance from bregma.
ANOVA of lever presses revealed a significant day by lever interaction effect $\left(\mathrm{F}_{(1,37)}=202.01, p<0.0001\right)$, significant day $\left(\mathrm{F}_{(1,37)}=61.77, \quad p<0.0001\right)$ and lever main effects $\left(\mathrm{F}_{(1,37)}=271.72, p<0.0001\right)$, but failed to show a day by

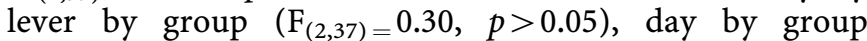
$\left(\mathrm{F}_{(2,37)}=0.08, p>0.05\right)$, or lever by group interaction effect $\left(\mathrm{F}_{(2,37)}=0.18, p>0.05\right)$, or a group main effect $\left(\mathrm{F}_{(2,37)}=0.38\right.$, $p>0.05)$. Subsequent simple main effect tests revealed a significant decrease in active lever response $\left(t_{(39)}=12.46\right.$, $p<0.0001)$ and an increase in inactive lever response $\left(t_{(39)}=-9.94, p<0.001\right)$ during extinction relative to selfadministration. Furthermore, the analyses showed significantly lower number of responses on the inactive lever relative to active lever during both self-administration $\left(t_{(39)}=-17.84, p<0.0001\right)$ and extinction $\left(t_{(39)}=-5.68\right.$, $p<0.0001)$.

\section{Response During Extinction and Conditioned-Cue Test Sessions}

Tests for order effects of treatment revealed no significant effects; thus, data were collapsed across test day order. Furthermore, there was no residual effect of amphetamine administration on active lever responding on subsequent days when animals received vehicle infusions. A mixed factor ANOVA revealed that there was a significant cue presentation main effect $\left(\mathrm{F}_{(1,19)}=21.31, p<0.0001\right)$, but there was no group by cue presentation interaction effect $\left(\mathrm{F}_{(2,19)}=0.84, p>0.05\right)$, nor was there a group main effect $\left(\mathrm{F}_{(2,19)}=3.26, p>0.05\right)$. Thus, there was no difference in active lever response between groups that received vehicle after a D-amphetamine infusion or after a vehicle infusion (eg vehicle only control group).

A $2 \times 2$ mixed factor ANOVA of active lever presses during extinction $v s$ testing in the absence of cues failed to reveal a test day by group interaction effect $\left(\mathrm{F}_{(1,31)}=0.18\right.$, $p>0.05)$, test day $\left(\mathrm{F}_{(1,31)}=0.47, p>0.05\right)$, or group main

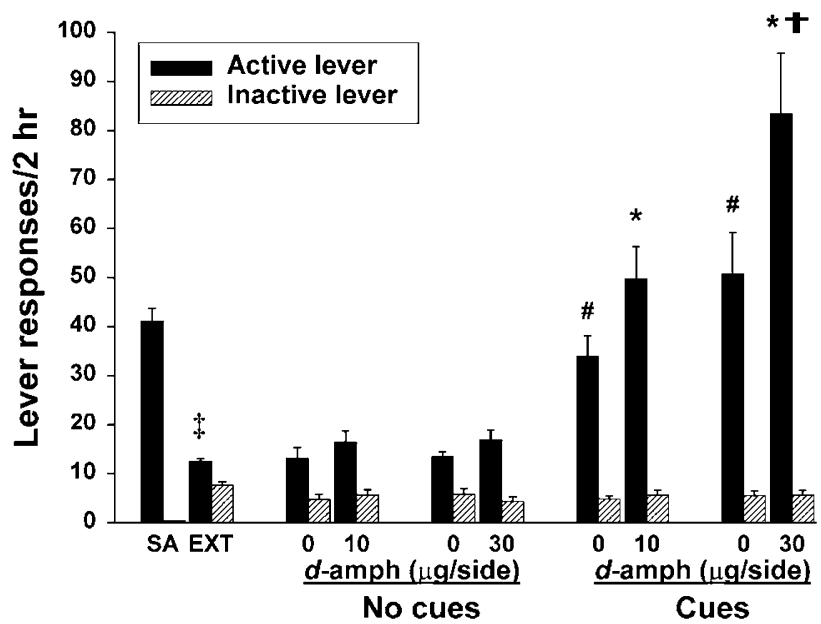

Figure 2 Responses on the active and inactive levers (mean \pm SEM) during self-administration (SA; mean of last 3 days), the last extinction day $(\mathrm{EXT})$, and testing in the absence and presence of the light + tone cues $\left({ }^{\ddagger} p<0.000\right.$ I, significant difference relative to active lever responding during $\mathrm{SA} ; \# p<0.000 \mathrm{I}$, significant difference relative to no cues testing days ${ }^{*} p<0.05$, significant difference relative to vehicle infusions; ${ }^{\dagger} p<0.05$ significant difference relative to $10 \mu \mathrm{g} /$ side of D-amphetamine). 
effect $\left(F_{(1,31)}=0.33, p>0.05\right)$. Thus, intra-BLA vehicle infusion had no effect on active lever response during no cues testing conditions relative to extinction response. A $2 \times 2$ mixed factor ANOVA of active lever presses during extinction $v s$ testing in the presence of cues revealed a test day main effect $\left(\mathrm{F}_{(1,31)}=32.42, p<0.0001\right)$, but failed to reveal a group main effect $\left(\mathrm{F}_{(1,31)}=2.72, p>0.05\right)$ or a test day by group interaction effect $\left(\mathrm{F}_{(1,31)}=2.61, p>0.05\right)$. Thus, the presence of cues was capable of reinstating lever responding on the active lever relative to response in the absence of cues.

In the absence of cues, intra-BLA D-amphetamine failed to alter responding on the active and inactive levers. A $2 \times 2$ mixed factor ANOVA of active lever presses in the absence of cue presentation failed to reveal a test day by group interaction effect $\left(\mathrm{F}_{(1,31)}=0.01, p>0.05\right)$, and test day $\left(\mathrm{F}_{(1,31)}=2.80, p>0.05\right)$ or group main effects $\left(\mathrm{F}_{(1,31)}=\right.$ $0.04, p>0.05)$. A similar analysis of inactive lever presses in the absence of cues failed to reveal a test day by group interaction effect $\left(\mathrm{F}_{(1,31)}=0.82, p>0.05\right)$ and test day $\left(\mathrm{F}_{(1,31)}=0.40, p>0.05\right)$ or group main effects $\left(\mathrm{F}_{(1,31)}=0.02\right.$, $p>0.05)$. Thus, in the absence of cues, there was no difference in responding on the active and inactive levers following 10 or $30 \mu \mathrm{g} /$ side of $\mathrm{D}$-amphetamine infusion into the BLA relative to vehicle infusion.

In contrast to response under extinction conditions, rats responded significantly more following intra-BLA D-amphetamine infusion than following a vehicle infusion in the presence of conditioned cues. A $2 \times 2$ mixed factor ANOVA of active lever presses in the presence of responsecontingent cues revealed significant test day $\left(\mathrm{F}_{(1,31)}=\right.$ $10.41, p<0.05)$ and group main effects $\left(\mathrm{F}_{(1,31)}=6.10\right.$, $p<0.05)$, but no test day by group interaction effect $\left(\mathrm{F}_{(1,31)}=1.29, p>0.05\right)$. Furthermore, a planned comparison indicated that the $30 \mu \mathrm{g} / \mathrm{side}$ dose group responded significantly more than the $10 \mu \mathrm{g} /$ side dose group following D-amphetamine infusion $\left(t_{(31)}=2.27, p<0.05\right)$, but not following vehicle infusion $\left(t_{(31)}=1.78, p>0.05\right)$. Potentiation of lever responding was limited to the previously drugpaired lever, in that analysis of inactive lever presses in the presence of response-contingent cues failed to reveal a test day by group interaction effect $\left(\mathrm{F}_{(1,31)}=0.20, p>0.05\right)$ and a test day $\left(\mathrm{F}_{(1,31)}=0.46, p>0.05\right)$ or group main effect $\left(\mathrm{F}_{(1,31)}=0.09, p>0.05\right)$.

\section{Temporal Analysis of Active Lever Response}

Further analysis of lever responding was conducted in order to ascertain the temporal pattern of D-amphetamineinduced potentiation of responding. D-Amphetamine dosedependently increased active lever responding during the first 30-min time bin (Figure 3). A $2 \times 3 \times 4$ repeated measures ANOVA of active lever responses during the last self-administration day $v s$ the vehicle and D-amphetamine conditioned-cued reinstatement test days revealed a significant three-way group by test day by time interaction effect $\left(\mathrm{F}_{(6,174)}=2.20, p<0.05\right)$, time by group $\left(\mathrm{F}_{(3,87)}=7.20\right.$, $p<0.0001)$ and test day by time interaction effects $\left(\mathrm{F}_{(6,174)}=4.40, p<0.0001\right)$, and test day $\left(\mathrm{F}_{(2,58)}=5.81\right.$, $p<0.01)$, time $\left(\mathrm{F}_{(3,87)}=23.32, p<0.0001\right)$, and group main effects $\left(\mathrm{F}_{(1,29)}=6.51, p<0.05\right)$. There was no test day by group interaction effect $\left(\mathrm{F}_{(2,58)}=1.88, p>0.05\right)$. Subsequent
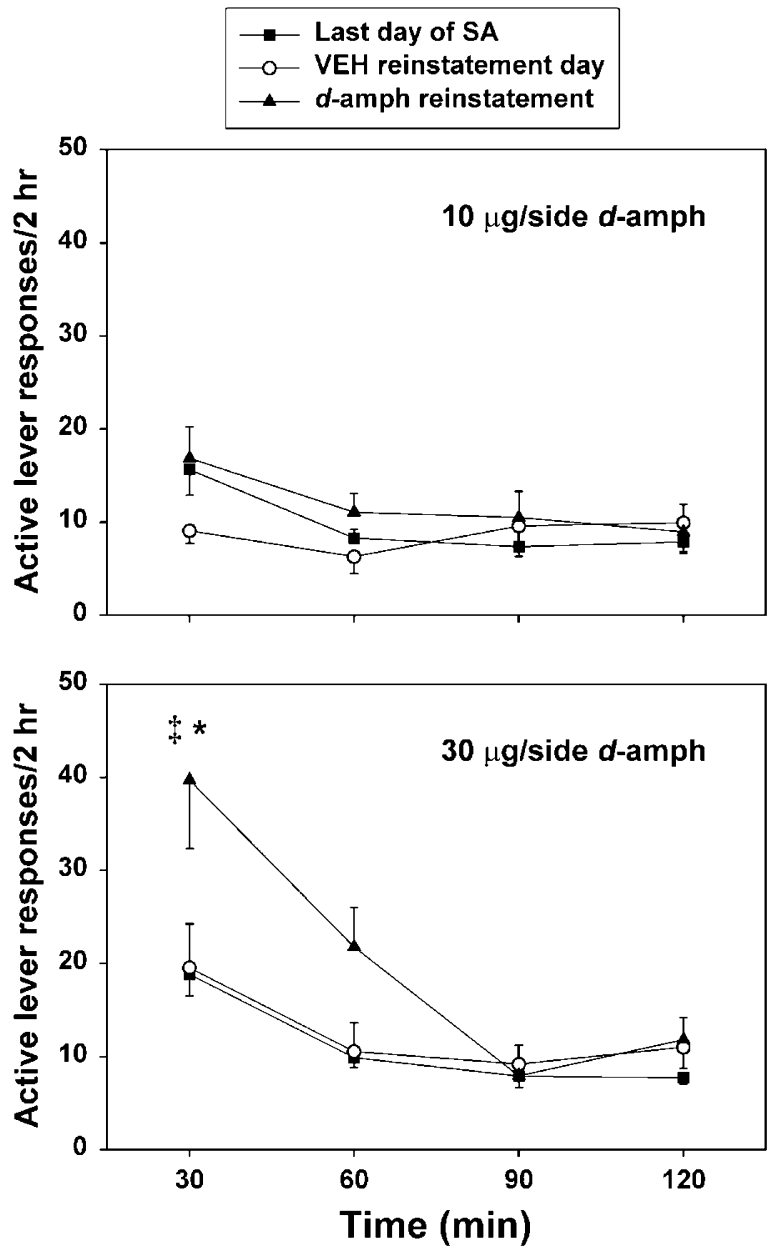

Figure 3 Time course of active lever responses on the last SA day and on the vehicle and D-amphetamine condition-cued reinstatement test days (mean \pm SEM). Top panel: effects of intra-BLA infusions of $10 \mu \mathrm{g} /$ side of $\mathrm{D}$ amphetamine. Bottom panel: effects of intra-BLA infusions of $30 \mu \mathrm{g} / \mathrm{side}$ of D-amphetamine ( ${ }^{*} p<0.05$, significant difference relative to vehicle infusion; ${ }_{p}^{\ddagger}<0.05$, significant difference relative to SA).

pairwise comparisons indicated that $10 \mu \mathrm{g} /$ side of $\mathrm{D}$ amphetamine did not significantly increase response relative to either the last day of self-administration (Tukey HSD, $p>0.05$ ) or the vehicle reinstatement test day (Tukey $\mathrm{HSD}, p>0.05)$. In contrast, the $30 \mu \mathrm{g} /$ side of $\mathrm{D}$-amphetamine significantly increased lever response in the presence of cues during the first 30 -min bin, relative to the last day of self-administration (Tukey HSD, $p<0.05$ ) or the vehicle reinstatement day (Tukey HSD, $p<0.05$ ). This potentiation was not significant following the first $30-\mathrm{min}$ bin.

\section{Locomotor Testing}

Intra-BLA D-amphetamine produced a modest increase in general motor activity as measured by the total number of beam breaks during the 1-h locomotor activity test $($ Vehicle $=1407 \pm 115 ; \quad 10 \mu \mathrm{g} /$ side $\quad$ D-amphetamine $=$ $1821 \pm 128 ; 30 \mu \mathrm{g} /$ side D-amphetamine $=1976 \pm 117) . \quad \mathrm{A}$ $2 \times 3$ mixed factor ANOVA of locomotor activity during $30-\mathrm{min}$ bins revealed significant time $\left(\mathrm{F}_{(1,33)}=203.02\right.$, 
$p<0.0001)$ and group main effects $\left(\mathrm{F}_{(1,33)}=6.49, p<0.01\right)$, but failed to show a time by group interaction effect $\left(\mathrm{F}_{(2,33)}=0.64, p>0.05\right)$. Collapsed across time, both 10 and $30 \mu \mathrm{g} /$ side of $\mathrm{D}$-amphetamine significantly increased locomotor activity relative to vehicle (Tukey HSD, $p<0.05$ ).

\section{DISCUSSION}

The present study represents the first demonstration of a site-selective pharmacological potentiation of conditionedcued reinstatement of drug-seeking behavior. Of critical note is the fact that intra-BLA D-amphetamine infusion in the absence of conditioned cues failed to reinstate extinguished response, but significantly enhanced response only in the presence of drug-paired cues. This effect stands in contrast to previous drug priming studies of reinstatement, whereby increased lever responding following extinction occurred in the absence of conditioned stimuli after direct intracranial drug application, specifically in the nucleus accumbens (Stewart and Vezina, 1988; Cornish et al, 1999; Cornish and Kalivas, 2000), prefrontal cortex (McFarland and Kalivas, 2001), and the ventral tegmental area (Stewart, 1984). Previous studies of conditioned-cued reinstatement using selective intracranial manipulation have only examined the pharmacological blockade of conditioned-cued reinstatement, with several studies demonstrating attenuation of increased lever responding after disruption of BLA function (Grimm and See, 2000; Kruzich and See, 2001; Fuchs and See, 2002; Kantak et al, 2002). Thus, intact function of the BLA is necessary for the utilization of previously learned stimulus-reward associations acquired during the time of active drug-taking. The present study extends our understanding of the role of the BLA in mediating these stimulus-reward associations by demonstrating the potentiation of response in the presence of enhanced DA levels.

In addition to extensive DA input from the ventral tegmental area, the BLA also receives substantial serotonin and moderate norepinephrine innervation from the dorsal raphe and locus coeruleus, respectively (Sadikot and Parent, 1990; Ma et al, 1991). Norepinephrine in the BLA is implicated in certain forms of associative learning, such as conditioned taste aversion (Borsini and Rolls, 1984), while serotonin has also been implicated in cocaine-seeking behavior (Tran-Nguyen et al, 1999, 2001; Baker et al, 2001). While it is well known that D-amphetamine potentiates the release and prevents the reuptake of catecholamines and serotonin (Moore, 1978), most evidence indicates that the primary effects of amphetamine in the central nervous system occur via enhanced DA neurotransmission (Zhang and Xu, 2001; Schenk, 2002). However, it will be important to examine the contribution of other amygdalar monoamines in the potentiation of conditionedcued reinstatement of cocaine-seeking behavior.

The facilitation of conditioned-cued reinstatement produced by amphetamine was apparent only during the initial half hour of the test session. This temporal pattern of enhanced response likely reflects the rapid action of amphetamine. Microdialysis studies in rats have shown that high concentrations of directly applied intracranial amphetamine produce a rapid and transient increase in DA efflux, followed by a rapid decrease in DA upon cessation of drug application (Zetterstrom et al, 1988; Nomikos et al, 1990). Furthermore, within session extinction of lever response for conditioned cues across the 2-h test session may be apparent even in the presence of residual amphetamine.

It is unlikely that D-amphetamine reward per se accounted for the potentiation of conditioned-cued reinstatement, since previous research indicates that the BLA does not generally mediate the rewarding effects of psychomotor stimulants and other primary reinforcers. Consistent with this idea, BLA lesions do not disrupt responding for water or access to an estrous female on a continuous reinforcement schedule (Cador et al, 1989; Everitt et al, 1989). Furthermore, intra-BLA infusion of D-amphetamine does not elicit conditioned place preference (O'Dell et al, 1999). These findings mitigate against the possibility that Damphetamine served simply as a drug prime in the present study, in addition to the already noted fact that intra-BLA infusions of $\mathrm{D}$-amphetamine did not alter responding under extinction conditions. It is possible that intra-BLA Damphetamine increased cocaine-seeking behavior via its generalized stimulant effects, since it did slightly increase general locomotor activity relative to vehicle infusions in a novel test environment. This effect is consistent with a previous study that has shown an increase in locomotor activity following intra-BLA administration of D-amphetamine (O'Dell et al, 1999). However, in the present study, slightly elevated locomotor activity was observed after both low- or high-dose amphetamine infusion, but only the high dose produced significant enhancement of conditionedcued reinstatement. In addition, the stimulant effects of Damphetamine infusion did not alter the specificity of operant responding, in that intra-BLA D-amphetamine did not increase responding on the inactive lever during conditioned-cued reinstatement testing, nor did it affect responding on either the active or inactive lever during extinction. Thus, it is unlikely that $\mathrm{D}$-amphetamine-induced hyperactivity alone was responsible for the potentiation of conditioned-cued reinstatement.

Previous reports indicate that DA levels in the amygdala become elevated during cocaine self-administration and cocaine-seeking behavior (Tran-Nguyen et al, 1998; Weiss et al, 2000). Specifically, during cocaine self-administration, DA levels increase in the amygdala and they are significantly higher than DA levels in animals who received passive infusions of cocaine (Wilson et al, 1994). Furthermore, DA levels increase in the amygdala following chronic cocaine intake during cocaine-seeking behavior in a cocaine-paired environment (Tran-Nguyen et al, 1998) and during reinstatement of extinguished cocaine-seeking behavior elicited by presentation of a cocaine-predictive CS + (Weiss et al, 2000). Similarly, a CS + paired with sucrose elicits an increase in DA overflow in the amygdala, while a CS - does not elicit the same DA increase (Harmer and Phillips, 1999). Collectively, these findings suggest that motivationally relevant cues influence DA levels in the amygdala and that DA in the amygdala may exert a formative role in stimulus-reward associations and subsequent goal-directed behavior.

DA D1 receptors in the BLA appear to play a critical role in conditioned-cued reinstatement of extinguished cocaine- 
seeking behavior. Systemically administered DA D1 receptor antagonists, such as SCH 39166 or SCH 23390, reduce cocaine-seeking behavior and Fos expression in the BLA and medial prefrontal cortex in the presence of a cocainepredictive stimulus (Ciccocioppo et al, 2001). Additionally, intra-BLA infusion of SCH 23390 abolishes the expression of conditioned-cued reinstatement of cocaine-seeking behavior (See et al, 2001). In contrast, intra-BLA infusion of raclopride, a selective DA D2 receptor antagonist, fails to alter cocaine-seeking behavior (See et al, 2001). These findings suggest that stimulation of DA D1 receptors is necessary for conditioned-cued reinstatement of cocaineseeking behavior. Direct application of selective DA D1 receptor agonists within the BLA would thus be predicted to enhance conditioned-cued reinstatement in a manner similar to that seen with amphetamine infusion in the present study.

While cocaine-paired stimuli may increase DA levels in the amygdala, that increase may in turn further facilitate processing of the sensory aspects of these stimuli, thereby potentiating their motivational salience. Electrophysiological studies suggest that DA in the BLA is a powerful modulator of the excitability of interneurons and projection neurons (Rosenkranz and Grace, 1999, 2001). DA receptor activation, upon application of DA in the BLA, appears to act as a 'noise filter' by inhibiting projection neurons and exciting interneurons via the stimulation of DA D1 receptors. The modulatory effects of DA, however, appear to be selective to the type of input received by the BLA. Specifically, sensory input appears to be potentiated by DA, while input from the medial prefrontal cortex is attenuated. As a result, it has been hypothesized that in the presence of increased DA neurotransmission in the BLA, only relatively strong neural inputs can drive amygdalar contribution to behavior (Rosenkranz and Grace, 1999, 2001). Thus, in the present study, cocaine-paired cues in the presence of enhanced intra-BLA DA may have been processed as stronger sensory stimuli. As a result, D-amphetamine may have increased the incentive-motivational salience of the cues and subsequently facilitated focused, cocaine-seeking behavior in response to these cocaine-paired cues via its action as an indirect DA agonist.

In conclusion, intra-BLA infusion of $\mathrm{D}$-amphetamine selectively potentiated extinguished cocaine-seeking behavior only in the presence of cues previously paired with drug-taking. This finding strengthens the idea that DA facilitates motivationally relevant sensory inputs into the amygdala. Dopaminergic modulation of the amygdala may serve to enhance emotive processing across a wide range of emotional stimuli, both positive and negative. For example, a recent fMRI study in humans showed that $\mathrm{D}$-amphetamine selectively potentiated amygdalar activation in the presence of angry or fearful visual stimuli (Hariri et al, 2002). Thus, dopaminergic modulation of the amygdala may serve as a key gating mechanism, whereby other regions of the brain that receive amygdalar inputs organize the ultimate behavioral response to specific emotive stimuli. By understanding the neurotransmitter regulation of the BLA during affective processing of relevant environmental stimuli, insights will be gained towards developing selective pharmacological treatments for conditioned craving and relapse to drug use.

\section{ACKNOWLEDGEMENTS}

We thank Allison Evans, William Berglind, and Macon Parker for their technical assistance. This research was supported by National Institute on Drug Abuse Grant DA10462 (RES) and the Air Force Institute of Technology (CCL).

\section{REFERENCES}

Baker DA, Tran-Nguyen TL, Fuchs RA, Neisewander JL (2001). Influence of individual differences and chronic fluoxetine treatment on cocaine-seeking behavior in rats. Psychopharmacology (Berl) 155: 18-26.

Borsini F, Rolls ET (1984). Role of noradrenaline and serotonin in the basolateral region of the amygdala in food preferences and learned taste aversions in the rat. Physiol Behav 33: 37-43.

Brinley-Reed M, McDonald AJ (1999). Evidence that dopaminergic axons provide a dense innervation of specific neuronal subpopulations in the rat basolateral amygdala. Brain Res 850: 127-135.

Cador M, Robbins TW, Everitt BJ (1989). Involvement of the amygdala in stimulus-reward associations: interaction with the ventral striatum. Neuroscience 30: 77-86.

Cador M, Taylor JR, Robbins TW (1991). Potentiation of the effects of reward-related stimuli by dopaminergic-dependent mechanisms in the nucleus accumbens. Psychopharmacology (Berl) 104: 377-385.

Carroll ME, Comer SD (1996). Animal models of relapse. Exp Clin Psychopharmacol 4: 11-18.

Childress AR, Hole AV, Ehrman RN, Robbins SJ, McLellan AT, O'Brien CP (1993). Cue reactivity and cue reactivity interventions in drug dependence. NIDA Res Monogr 137: 73-95.

Childress AR, McLellan AT, Ehrman R, O’Brien CP (1988). Classically conditioned responses in opioid and cocaine dependence: a role in relapse? NIDA Res Monogr 84: 25-43.

Childress AR, Mozley PD, McElgin W, Fitzgerald J, Reivich M, O'Brien CP (1999). Limbic activation during cue-induced cocaine craving. Am J Psychiatry 156: 11-18.

Ciccocioppo R, Sanna PP, Weiss F (2001). Cocaine-predictive stimulus induces drug-seeking behavior and neural activation in limbic brain regions after multiple months of abstinence: reversal by D1 antagonists. Proc Natl Acad Sci USA 98: 19761981.

Cornish JL, Duffy P, Kalivas PW (1999). A role for nucleus accumbens glutamate transmission in the relapse to cocaineseeking behavior. Neuroscience 93: 1359-1367.

Cornish JL, Kalivas PW (2000). Glutamate transmission in the nucleus accumbens mediates relapse in cocaine addiction. $J$ Neurosci 20: RC89.

Davis WM, Smith SG (1976). Role of conditioned reinforcers in the initiation, maintenance and extinction of drug-seeking behavior. Pavlovian J Biol Sci 11: 222-236.

de Wit H, Stewart J (1981). Reinstatement of cocainereinforced responding in the rat. Psychopharmacology (Berl) 75: $134-143$.

Everitt BJ, Cador M, Robbins TW (1989). Interactions between the amygdala and ventral striatum in stimulus-reward associations: studies using a second-order schedule of sexual reinforcement. Neuroscience 30: 63-75.

Fallon JH, Koziell DA, Moore RY (1978). Catecholamine innervation of the basal forebrain. II. Amygdala, suprarhinal cortex and entorhinal cortex. J Comp Neurol 180: 509-532.

Fuchs RA, See RE (2002). Basolateral amygdala inactivation abolishes conditioned stimulus- and heroin-induced reinstatement of extinguished heroin-seeking behavior in rats. Psychopharmacology (Berl) 160: 425-433. 
Fuchs RA, Tran-Nguyen LT, Specio SE, Groff RS, Neisewander JL (1998). Predictive validity of the extinction/reinstatement model of drug craving. Psychopharmacology (Berl) 135: 151-160.

Grant S, London ED, Newlin DB, Villemagne VL, Liu X, Contoreggi $C$ et al (1996). Activation of memory circuits during cue-elicited cocaine craving. Proc Natl Acad Sci USA 93: 12040-12045.

Grimm JW, See RE (2000). Dissociation of primary and secondary reward-relevant limbic nuclei in an animal model of relapse. Neuropsychopharmacology 22: 473-479.

Hariri AR, Mattay VS, Tessitore A, Fera F, Smith WG, Weinberger DR (2002). Dextroamphetamine modulates the response of the human amygdala. Neuropsychopharmacology 27: 1036-1040.

Harmer CJ, Phillips GD (1999). Enhanced dopamine efflux in the amygdala by a predictive, but not a non-predictive, stimulus: facilitation by prior repeated D-amphetamine. Neuroscience 90 $119-130$.

Hatfield T, Han JS, Conley M, Gallagher M, Holland P (1996). Neurotoxic lesions of basolateral, but not central, amygdala interfere with Pavlovian second-order conditioning and reinforcer devaluation effects. J Neurosci 16: 5256-5265.

Kantak KM, Black Y, Valencia E, Green-Jordan K, Eichenbaum HB (2002). Dissociable effects of lidocaine inactivation of the rostral and caudal basolateral amygdala on the maintenance and reinstatement of cocaine-seeking behavior in rats. $J$ Neurosci 22: 1126-1136.

Kruzich PJ, See RE (2001). Differential contributions of the basolateral and central amygdala in the acquisition and expression of conditioned relapse to cocaine-seeking behavior. J Neurosci 21: RC155.

Ma QP, Yin GF, Ai MK, Han JS (1991). Serotonergic projections from the nucleus raphe dorsalis to the amygdala in the rat. Neurosci Lett 134: 21-24.

Markou A, Weiss F, Gold LH, Caine SB, Schulteis G, Koob GF (1993). Animal models of drug craving. Psychopharmacology (Berl) 112: 163-182.

McFarland K, Kalivas P (2001). The circuitry mediating cocaineinduced reinstatement of drug-seeking behavior. J Neurosci 21: $8655-8663$.

Meil WM, See RE (1996). Conditioned cued responding following prolonged withdrawal from self-administered cocaine in rats: an animal model of relapse. Behav Pharmacol 7: 754-763.

Meil WM, See RE (1997). Lesions of the basolateral amygdala abolish the ability of drug associated cues to reinstate responding during withdrawal from self-administered cocaine. Behav Brain Res 87: 139-148.

Moore KE (1978). Amphetamines: biochemical and behavioral actions in animals. In: Iversen LL, Iversen SD, Snyder SH (eds) Handbook of Psychopharmacology. Plenum Press: New York. pp 41-98.

Neisewander JL, Baker DA, Fuchs RA, Tran-Nguyen LT, Palmer A, Marshall JF (2000). Fos protein expression and cocaine-seeking behavior in rats after exposure to a cocaine self-administration environment. J Neurosci 20: 798-805.

Nomikos GG, Damsma G, Wenkstern D, Fibiger HC (1990). In vivo characterization of locally applied dopamine uptake inhibitors by striatal microdialysis. Synapse 6: 106-112.

O'Brien CP, Childress AR, McLellan T, Ehrman R (1990). Integrating systemic cue exposure with standard treatment in recovering drug dependent patients. Addict Behav 15: 355-365.

O’Brien CP, Childress AR, McLellan AT, Ehrman R (1992). Classical conditioning in drug-dependent humans. Ann NY Acad Sci 654: 400-415.

O’Dell LE, Sussman AN, Meyer KL, Neisewander JL (1999). Behavioral effects of psychomotor stimulant infusions into amygdaloid nuclei. Neuropsychopharmacology 20: 591-602.
Paxinos G, Watson D (1986). The Rat Brain in Stereotaxic Coordinates. Academic Press: New York.

Rosenkranz JA, Grace AA (1999). Modulation of basolateral amygdala neuronal firing and afferent drive by dopamine receptor activation in vivo. J Neurosci 19: 11027-11039.

Rosenkranz JA, Grace AA (2001). Dopamine attenuates prefrontal cortical suppression of sensory inputs to the basolateral amygdala of rats. J Neurosci 21: 4090-4103.

Sadikot AF, Parent A (1990). The monoaminergic innervation of the amygdala in the squirrel monkey: an immunohistochemical study. Neuroscience 36: 431-447.

Schenk JO (2002). The functioning neuronal transporter for dopamine: kinetic mechanisms and effects of amphetamines, cocaine and methylphenidate. Prog Drug Res 59: 111-131.

See RE, Grimm JW, Kruzich PJ (2001). Dopamine, but not glutamate, receptor blockade in the basolateral amygdala attenuates conditioned reward in a rat model of relapse to cocaine-seeking behavior. Psychopharmacology (Berl) 154: 301310.

See RE, Grimm JW, Kruzich PJ, Rustay N (1999). The importance of a compound stimulus in conditioned drug-seeking behavior following one week of extinction from self-administered cocaine in rats. Drug Alcohol Depend 57: 41-49.

Stewart J (1984). Reinstatement of heroin and cocaine selfadministration behavior in the rat by intracerebral application of morphine in the ventral tegmental area. Pharmacol Biochem Behav 20: 917-923.

Stewart J, de Wit H, Eikelboom R (1984). Role of unconditioned and conditioned drug effects in the self-administration of opiates and stimulants. Psychol Rev 91: 251-268.

Stewart J, Vezina P (1988). A comparison of the effects of intraaccumbens injections of amphetamine and morphine on reinstatement of heroin intravenous self-administration behavior. Brain Res 457: 287-294.

Taylor JR, Robbins TW (1984). Enhanced behavioural control by conditioned reinforcers following microinjections of D-amphetamine into the nucleus accumbens. Psychopharmacology (Berl) 84: 405-412.

Taylor JR, Robbins TW (1986). 6-Hydroxydopamine lesions of the nucleus accumbens, but not of the caudate nucleus, attenuate enhanced responding with reward-related stimuli produced by intra-accumbens D-amphetamine. Psychopharmacology (Berl) 90: 390-397.

Tran-Nguyen LT, Baker DA, Grote KA, Solano J, Neisewander JL (1999). Serotonin depletion attenuates cocaine-seeking behavior in rats. Psychopharmacology (Berl) 146: 60-66.

Tran-Nguyen LT, Bellew JG, Grote KA, Neisewander JL (2001). Serotonin depletion attenuates cocaine seeking but enhances sucrose seeking and the effects of cocaine priming on reinstatement of cocaine seeking in rats. Psychopharmacology (Berl) 157: 340-348.

Tran-Nguyen LT, Fuchs RA, Coffey GP, Baker DA, O'Dell LE, Neisewander JL (1998). Time-dependent changes in cocaineseeking behavior and extracellular dopamine levels in the amygdala during cocaine withdrawal. Neuropsychopharmacology 19: 48-59.

Weiss F, Maldonado-Vlaar CS, Parsons LH, Kerr TM, Smith DL, Ben-Shahar O (2000). Control of cocaine-seeking behavior by drug-associated stimuli in rats: effects on recovery of extinguished operant-responding and extracellular dopamine levels in amygdala and nucleus accumbens. Proc Natl Acad Sci USA 97: $4321-4326$

Whitelaw RB, Markou A, Robbins TW, Everitt BJ (1996). Excitotoxic lesions of the basolateral amygdala impair the acquisition of cocaine-seeking behaviour under a second-order schedule of reinforcement. Psychopharmacology (Berl) 127: 213224. 
Wilson JM, Nobrega JN, Corrigall WA, Coen KM, Shannak K, Kish SJ (1994). Amygdala dopamine levels are markedly elevated after self- but not passive-administration of cocaine. Brain Res 668: 39-45.

Zetterstrom T, Sharp T, Collin AK, Ungerstedt U (1988). In vivo measurement of extracellular dopamine and DOPAC in rat striatum after various dopamine-releasing drugs; implications for the origin of extracellular DOPAC. Eur J Pharmacol 148: 327334.

Zhang J, Xu M (2001). Toward a molecular understanding of psychostimulant actions using genetically engineered dopamine receptor knockout mice as model systems. J Addict Dis 20: 7-18. 